\title{
Espécies de Parmotrema (Parmeliaceae, Ascomycetes liquenizados) com rizinas dimórficas do litoral centro-sul do Estado de São Paulo
}

\author{
Marcelo Pinto Marcelli ${ }^{1,2}$ e Michel Navarro Benatti ${ }^{1}$
}

Recebido: 23.08.2007; aceito: 24.04 .2008

\begin{abstract}
Species of Parmotrema (Parmeliaceae, lichenized Ascomycetes) with dimorphic rhizinae in the center-south coast of São Paulo State). In a survey of the species pertaining to genera of large parmeliae occurring in the coastal areas of the center-south coast of São Paulo State, Brazil, four species of Parmotrema with dimorphic rhizinae and effigurate maculae (P. consors (Nyl.) Krog \& Swinscow, P. fumarprotocetraricum Marcelli \& Hale, P. neotropicum Kurokawa in Hale and P. subcaperatum (Kremp.) Hall), formerly attributed to Canomaculina, were found. Identification key, descriptions, commentaries, and illustrations based on studied material are provided for these species.
\end{abstract}

Key words: Canomaculina, mangrove, Parmotrema, restinga

RESUMO - (Espécies de Parmotrema (Parmeliaceae, Ascomycetes liquenizados) com rizinas dimórficas do litoral centro-sul do Estado de São Paulo). O levantamento das espécies pertencentes aos gêneros de grandes parmélias do litoral centro-sul do Estado de São Paulo revelou quatro espécies de Parmotrema com rizinas dimórficas e máculas efiguradas (P. consors (Nyl.) Krog \& Swinscow, P. fumarprotocetraricum Marcelli \& Hale, P. neotropicum Kurokawa in Hale and P. subcaperatum (Kremp.) Hall), anteriormente referidas ao gênero Canomaculina. São apresentados chave de identificação, descrições detalhadas, comentários e ilustrações baseados no material estudado.

Palavras-chave: Canomaculina, manguezal, Parmotrema, restinga

\section{Introdução}

O grupo de espécies objetivo deste estudo é formado por 26 espécies, sendo quinze delas conhecidas para o Brasil (Marcelli 2005). Destas, nove são conhecidas para o Estado de São Paulo (Fleig 1997, Ribeiro 1998, Benatti 2005, Jungbluth 2006).

As espécies de Parmotrema aqui apresentadas estavam, até há pouco tempo, incluídas em Canomaculina Elix \& Hale. Porém, estudos recentes de biologia molecular demonstraram que Parmotrema e Canomaculina são congêneres (Blanco et al. 2005). Apesar dos dados moleculares corroborarem a sinonimização dos gêneros, os próprios autores mencionaram que este grupo de espécies é ainda complicado, e que mais estudos poderiam implicar em novas organizações genéricas em grupos menores a partir de caracteres morfológicos comuns.

As espécies do grupo são caracterizadas pelo córtex superior efiguradamente maculado, presença de cílios marginais comumente ramificados, margem inferior rizinada, rizinas dimórficas, apotécios freqüentemente perfurados e conídios cilíndricos a filiformes (Elix 1997). Devido às aparentes confusões na literatura do emprego do termo dimorfismo para as rizinas, o conceito seguido neste trabalho foi o definido por Kurokawa (1991), o qual considera que ocorrem, num mesmo talo, rizinas longas, espessas e de ápices ramificados, responsáveis por sua fixação ao substrato, misturadas com rizinas curtas, finas e simples, e que não se fixam.

O trabalho objetivou estudar as espécies do grupo que ocorrem nos biomas e em áreas urbanizadas do litoral centro-sul paulista. São fornecidos uma chave artificial de identificação, descrições comentadas, dados das localidades e de ambientes para as espécies encontradas.

\section{Material e métodos}

Foram analisadas amostras de coletas recentes e dos últimos 30 anos em todos os municípios da Baixada Santista localizados no litoral centro-sul do Estado de São Paulo, situados abaixo do trópico de Capricórnio e compreendidos entre os Municípios de Bertioga (23⒌ $17^{\prime}$ 'S, 4608'03”W) e Cananéia

1. Instituto de Botânica, Caixa Postal 3005, 01061-970 São Paulo, SP, Brasil

2. Autor para correspondência: mpmarcelli@msn.com 
(2500'53”S, 475'33”W). Dados geográficos, ambientais e de substratos disponíveis na região podem ser encontrados em Benatti \& Marcelli (2008).

A metodologia utilizada encontra-se descrita em Benatti \& Marcelli (2008). O material foi coletado e identificado conforme Fink (1905), Galloway (1985) e Hale (1979). Foram realizadas excursões pontuais de coleta a várias localidades urbanas e naturais de todos os municípios da região, tendo sido obtidas amostras de todos os ecossistemas costeiros que compõem a área de estudo. Amostras obtidas nas últimas décadas também foram estudadas.

A metodologia de análises químicas utilizadas seguiu Asahina \& Shibata (1954), Walker \& James (1980), White \& James (1985), Huneck \& Yoshimura (1996), Bungartz (2001) e Orange et al. (2001), com pequenas mudanças ou adaptações. Foram feitas análises por testes de coloração e por cromatografia em camada delgada (CCD) em solvente $\mathrm{C}$.

\section{Resultados}

No litoral centro-sul do Estado de São Paulo foram encontradas quatro espécies de Parmotrema com rizinas dimórficas e máculas efiguradas. Há apenas dois trabalhos brasileiros publicados com citação de material, que descrevem espécies desse grupo (Eliasaro \& Adler 2000, Eliasaro \& Donha 2003), anteriormente conhecidas sob o gênero Canomaculina, para o Estado do Paraná. Dentre os trabalhos estrangeiros que mencionam material brasileiro, há estudos de espécies do grupo feitas por Hale (1965, 1976, 1986) e Kurokawa (1991).

As espécies aqui tratadas foram apenas mencionadas para o Estado de São Paulo em trabalhos efetivamente publicados, sendo que os demais dados como descrições, comentários e chaves de identificação constam somente de teses e dissertações (Fleig 1997, Ribeiro 1998, Eliasaro 2001, Benatti 2005, Canêz 2005, Donha 2005, Spielmann 2005, Jungbluth 2006).

Nenhuma das espécies encontradas apresenta propagação por sorédios. Os talos de P. consors (Nyl.) Krog \& Swinscow e P. subcaperatum (Kremp.) Hale apresentam somente formação de apotécios, enquanto que espécimes de $P$. fumarprotocetraricum Marcelli $\&$ Hale e P. neotropicum Kurokawa apresentam formação de isídios.

Foram encontrados ascósporos somente nos apotécios de espécimes das duas espécies que não se reproduzem por propagação vegetativa, enquanto conídios estavam presentes em quase todos os espécimes analisados.

A tabela 1 mostra as relações entre os caracteres químicos, a coloração do córtex inferior, e os modos de reprodução das espécies encontradas, bem como dados sobre os ascósporos e conídios observados no material. O ácido salazínico é o componente químico mais comum nas espécies do grupo. Nenhum espécime contendo cloroatranorina foi encontrado, e grande parte dos espécimes de $P$. neotropicum não apresentou qualquer traço de ácido úsnico.

Tabela 1. Comparação entre as principais características das espécies de Parmotrema com rizinas dimórficas encontradas no litoral centro-sul do Estado de São Paulo.

\begin{tabular}{|c|c|c|c|c|c|}
\hline Espécie & $\begin{array}{l}\text { Ácido medular } \\
\text { principal }\end{array}$ & $\begin{array}{l}\text { Córtex } \\
\text { inferior }\end{array}$ & Reprodução & $\begin{array}{l}\text { Esporos } \\
(\mu \mathrm{m})\end{array}$ & $\begin{array}{l}\text { Conídios } \\
(\mu \mathrm{m})\end{array}$ \\
\hline P. consors & nenhum (graxos?) & $\begin{array}{c}\text { marrom-escuro a } \\
\text { negro, margens } \\
\text { marrons }\end{array}$ & apotécios & $\begin{array}{c}11,5-16,0 \\
\times(6,5-) 9,0-10,0\end{array}$ & $7,5-12,5$ \\
\hline P. fumarprotocetraricum & fumarprotocetrárico & $\begin{array}{l}\text { marrom a negro, } \\
\text { margem marrom- } \\
\text { clara }\end{array}$ & isídios & desconhecidos & $6,5-10,0$ \\
\hline P. neotropicum & salazínico & $\begin{array}{l}\text { marrom a negro, } \\
\text { margem marrom- } \\
\text { clara }\end{array}$ & isídios & desconhecidos & $6,5-9,0$ \\
\hline P. subcaperatum & salazínico & $\begin{array}{l}\text { marrom-claro a } \\
\text { escuro, margem } \\
\text { marrom-clara }\end{array}$ & apotécios & $\begin{array}{r}14,0-16,0(-19,0) \\
\times 9,0-11,0(-14,0)\end{array}$ & $\begin{array}{l}5,0-9,0 \\
(-11,5)\end{array}$ \\
\hline
\end{tabular}


Chave para as espécies de Parmotrema com rizinas dimórficas do litoral centro-sul do Estado de São Paulo

1. Talo sem isídios, normalmente com apotécios

2. Lado de baixo de negro a marromescuro, com margens marrons distintas; medula com todos os testes negativos

P. consors

2. Lado de baixo uniformemente marrom a marrom-claro, i.e., sem margens distintas; medula $\mathrm{K}+$ amarelo $\rightarrow$ vermelho, com ácido salazínico

P. subcaperatum

1. Talo com isídios, às vezes podendo formar apotécios

3. Medula $\mathrm{K}+$ amarelo $\rightarrow$ vermelho e $\mathrm{P}+$ amarelo, com ácido salazínico P. neotropicum

3. MedulaK+alaranjado $\rightarrow$ vermelhoamarronzado e $\mathrm{P}+$ alaranjado, com ácido fumarprotocetrárico.

\section{$P$. fumarprotocetraricum}

Parmotrema consors (Nyl.) Krog \& Swinscow, The Lichenologist 15(2): 129. 1983 = Parmelia consors Nyl., Flora 68: 613. 1885. Tipo: BRASIL. Minas GERAIs: Weddell s.n. (lectótipo H-NYL, n.v.).

Figuras 1a, b

Talo sublobado, verde-acinzentado a pardoesverdeado em herbário, de até 19,0 cm diâm., subcoriáceo, corticícola; lobos de ramificação irregular, $(1,0-) 2,0-6,5(-7,5) \mathrm{mm}$ larg., de contíguos a pouco sobrepostos lateralmente ou raramente amontoados no centro, de adnatos a pouco adnatos, pouco adpressos, os ápices subarredondados a subtruncados, planos a subplanos, raramente involutos, as margens crenadas a crenuladas, incisas, de superfície contínua e lisa; lacínulas ausentes, às vezes alguns lóbulos jovens irregulares surgindo em partes velhas do centro, planos, curtos, 0,3-1,8(-3,6) × 0,2-1,4 mm, simples ou irregulares, subarredondados ou truncados, ciliados, de lado de baixo concolorido à margem inferior do talo; máculas laminais fracas a distintas, mais distintas quando nos anfitécios, puntiformes, não originando quebras; cílios negros, de simples a furcados, dicotômicos ou cespitosos, 0,1-1,6 × 0,05-0,15 mm, abundantes, distribuídos por toda a margem, surgindo principalmente nas axilas de crenas e crênulas. Sorais, pústulas e isídios ausentes. Medula branca, sem pigmentações. Lado de baixo negro a marrom muito escuro, lustroso, liso a pouco rugoso e pouco papilado; margem marrom, lustrosa, $(0,5)$ 2,0-6,0(-8,0) $\mathrm{mm}$, atenuada mesclando-se ao centro, lisa, papilada e em parte rizinada; rizinas concolores ou negras, dimórficas (às vezes não muito evidentes), agudas a retorcidas, as menores simples e finas, as maiores furcadas, irregulares ou esquarrosas, de espessura variável, $0,20-2,50 \times$ ca. $0,05-0,15(-0,20)$ $\mathrm{mm}$, abundantes, homogeneamente distribuídas. Apotécios de subcôncavos a cupuliformes, 0,4-10,4 $\mathrm{mm}$, de laminais a submarginais, subpedicelados, margem lisa e não ornamentada, anfitécio liso ou às vezes pouco rugoso e mais escuro que o córtex superior, tornando-se fendidos, retorcidos ou involutos quando velhos; disco marrom-claro, subcôncavo a cupuliforme, não pruinoso, perfurado; ascósporos elipsóides, 11,5-16,0 × (6,5-)9,0-10,0 $\mu \mathrm{m}$, epispório ca. 1,0 $\mu \mathrm{m}$ de espessura. Picnídios submarginais, às vezes laminais, de ostíolo negro; conídios filiformes curtos, 7,5-12,5 × ca. 1,0 $\mu \mathrm{m}$.

Testes de coloração e substâncias de importância taxonômica: córtex superior $\mathrm{K}+$ amarelo, UV(atranorina); medula $\mathrm{K}-, \mathrm{C}-, \mathrm{KC}-, \mathrm{P}-, \mathrm{UV}-$ (nenhum ácido liquênico foi encontrado em cromatografia).

Distribuição: Oceania e América do Sul. Brasil: MT, MG, SP, RJ, PR, SC, RS (Hale 1976, Elix 1994, Ribeiro 1998, Eliasaro 2001, Eliasaro \& Adler 2000, Eliasaro \& Donha 2003, Benatti 2005, Canêz 2005, Spielmann 2005, Jungbluth 2005).

Material estudado: BRASIL. São Paulo: Peruíbe, Reserva Ecológica Juréia-Itatins, Núcleo Guarauzinho, no sopé da Serra do Mar, ao redor da sede, 26-VII-1993, M.P. Marcelli \& O. Yano 23695 (SP); idem, 26-VII-1993, M.P. Marcelli \& O. Yano 23696 (SP); Praia Grande, Jardim Real, terreno baldio na zona urbana ca. $1,5 \mathrm{~km}$ da praia, 15-XII2003, M.N. Benatti \& M.P. Marcelli 1644 (SP); idem, Jardim Solemar, horto florestal junto à escola municipal Cidade da Criança, 15-XII-2003, M.N. Benatti \& M.P. Marcelli 1647 (SP); São Sebastião, Centro de Biologia Marinha (CEBIMAR) da USP, próximo à escada para o auditório no morro, 18-III1988, M.P. Marcelli 2072 (SP); idem, a 30 metros da praia, atrás da casa dos barcos, 18-III-1988, M.P. Marcelli 2175 (SP); idem, na praia, 18-III1988, M.P. Marcelli 2198 (SP); idem, 18-III-1988, M.P. Marcelli 2000 (SP); idem, 18-III-1988, M.P. Marcelli 2202 (SP). 


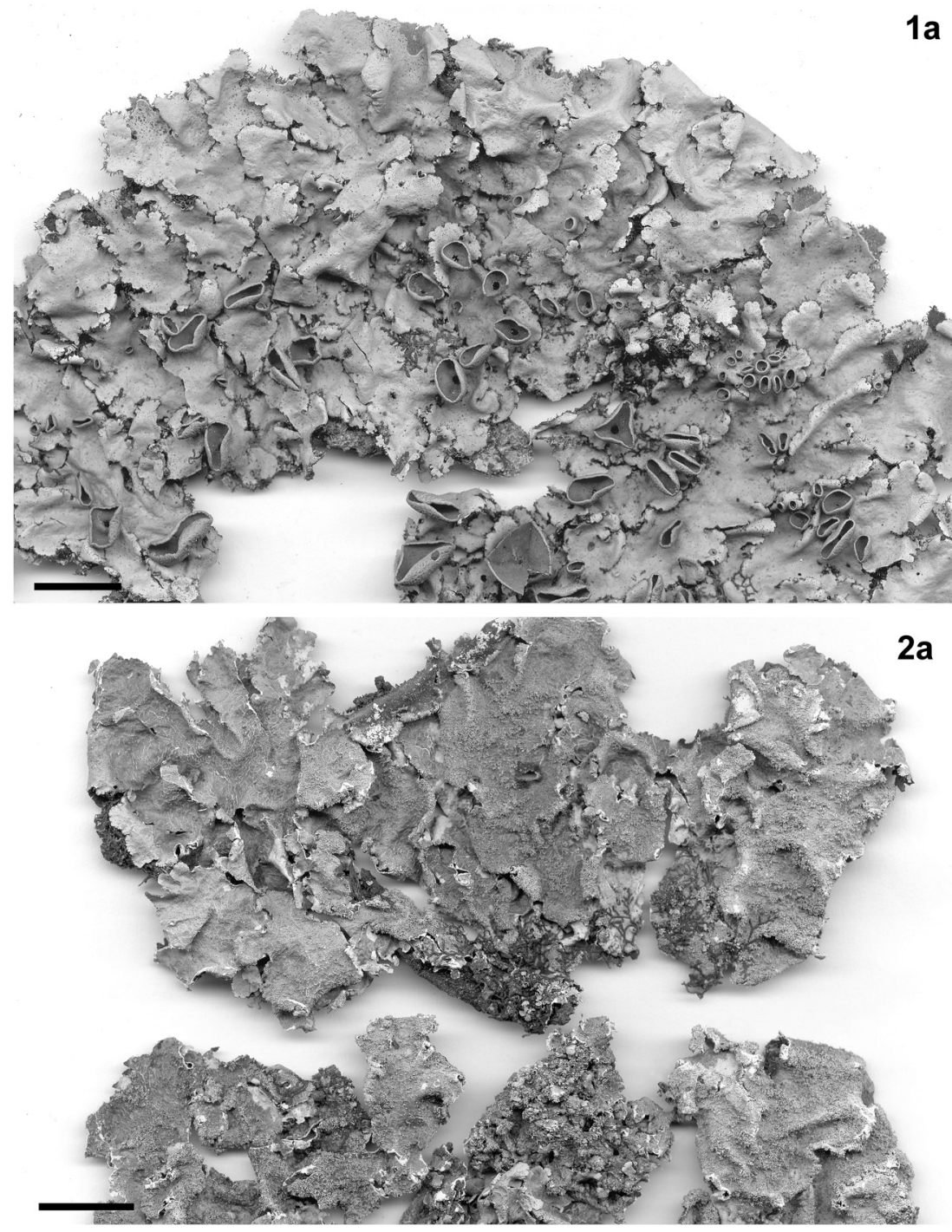

$1 \mathbf{a}$
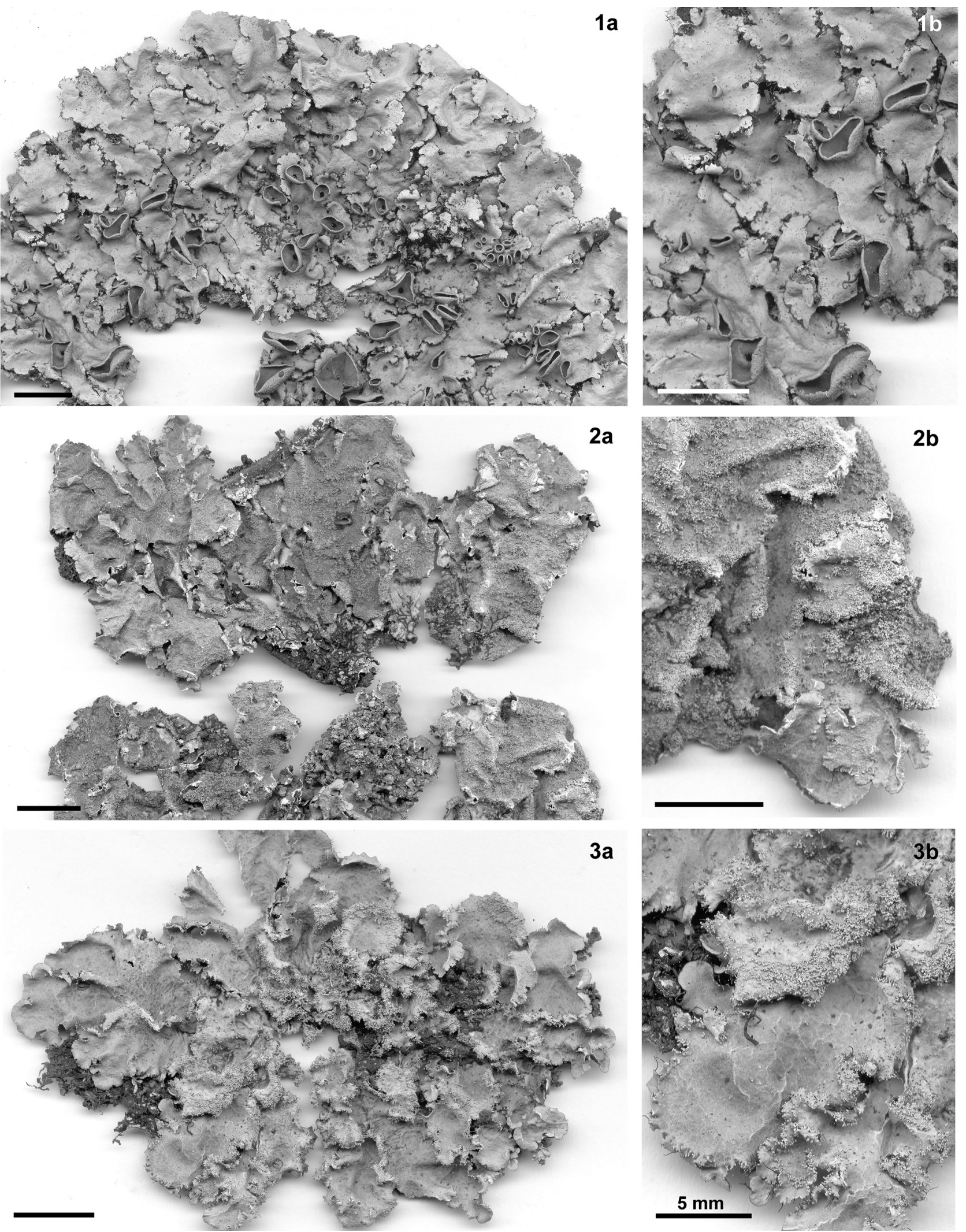

Figura 1. Parmotrema consors. a. Hábito. b. Detalhe (Marcelli 23695). Figura 2. Parmotrema fumarprotocetraricum. a. Hábito. b. Detalhe (Marcelli 1681, isoparátipo). Figura 3. Parmotema neotropicum. a. Hábito. b. Detalhe (Marcelli 4711). Barras de escala $=1 \mathrm{~cm}$, exceto onde indicado. 
Parmotrema consors é caracterizada pela ausência de propágulos vegetativos, córtex inferior negro a marrom muito escuro com as margens marrons mais claras e todos os testes químicos medulares negativos. Os lobos são bastante crenados, sem tendência a formar lacínulas, e tanto as rizinas quanto os cílios apresentam variações de ramificação e espessura conforme se desenvolvem.

Em todos os espécimes analisados, notouse que as rizinas não apresentam um dimorfismo tão evidenciado quanto o que ocorre em outras espécies do grupo, como facilmente perceptível em Parmotrema subcaperatum. Quando próximas às margens, as rizinas tendem a ser mais finas e agudas, e conforme se observa seu desenvolvimento para o centro do talo, atingem comprimentos e espessuras variadas, tornando-se mais arcuadas e ramificando de modos diferentes. Os estágios intermediários entre as rizinas menores e maiores são tantos, que em nenhum momento foi possível detectar algum trecho em que grupos bem definidos de rizinas curtas e finas misturadas a outras longas e grossas, pudessem ser claramente percebidos, mas apenas variações entre as quantidades de umas e de outras.

A literatura (e.g., Kurokawa 1991, 2001, Elix 1994, 1997) cita esta espécie como tendo rizinas dimórficas, entretanto, o material observado de Parmotrema consors e também de outras espécies (particularmente as de córtex inferior escuro) deixa dúvidas quanto ao que está sendo chamado de dimorfismo. Poucos trabalhos, tais como os acima citados, definem explicitamente o conceito adotado, sendo que as descrições encontradas tendem a ser muito curtas e diretas.

Nesta espécie, os apotécios são quase sempre perfurados desde jovens, enquanto os poucos não perfurados apresentam algumas depressões estreitas centrais nos discos e que provavelmente estão relacionadas às perfurações. Notou-se também que, apesar de serem ainda mais evidentemente maculados que as demais partes do talo, os apotécios são em geral de tonalidade mais escura que a do córtex superior, tornando-se pardacentos quando velhos.

Tanto Parmotrema uruguense (Kremp.) Hale como $P$. subcaperatum diferem de $P$. consors por apresentarem córtex inferior marrom (claro ou parcialmente mais escuro) e ácidos salazínico e consalazínico medulares, sendo que por sua vez, $P$. uruguense ainda pode ser distinguida pelos apotécios ciliados (Kurokawa 1991, Fleig 1997). Pelas descrições e comentários de Kurokawa (1991) e Fleig (1997), P. recipiendum é semelhante na morfologia a $P$. consors, mas difere por apresentar norlobaridona e loxodina (KC+ róseo a avermelhado) na medula. Os lobos nesta espécie são ainda bem mais largos (0,7-2,0 $\mathrm{cm})$ que os vistos no material de $P$. consors estudado neste trabalho. Espécimes de $P$. macrocarpum diferem pelas margens sublacinuladas com lacínulas curtas e planas, córtex superior reticulado-maculado com quebras rimosas, cílios geralmente simples, e por apresentar ácido caperático na medula (Benatti 2005, Benatti \& Marcelli 2008).

Quando presente, o ácido caperático, e outros ácidos não detectáveis por testes de coloração (graxos), são acusados em cromatografia. O que se percebe é que os espécimes de Parmotrema consors analisados produzem somente atranorina no talo, concordando com Hale (1976) e Sipman (2004), ainda que algumas citações em literatura afirmem a ocorrência de ácidos graxos na espécie (Elix \& Hale 1987, Ribeiro 1998, Eliasaro 2001, Spielmann 2005), porém sem especificarem quais os tipos de ácidos encontrados. Contudo, Spielmann obteve indícios de que a substância encontrada em seu material não é o ácido caperático (Spielmann, dados não publicados).

Parmotrema fumarprotocetraricum Marcelli \& Hale, Mycotaxon 25: 88. 1986. Tipo: BRASIL. São PAUlo: Itanhaém, manguezal próximo à ponte sobre o Rio Itanhaém, km 112 da BR-101, M.P. Marcelli 8 (holótipo US, n.v.).

Figuras 2a, b

Talo sublobado, verde-acinzentado a pardoesverdeado-claro quando em herbário, até $10,5 \mathrm{~cm}$ diâm., subcoriáceo, corticícola; lobos de ramificação irregular, 3,0-11,5 mm, de sobrepostos lateralmente a parcialmente amontoados no centro, de adnatos a elevados, pouco adpressos, os ápices subarredondados, de planos a subplanos, as margens crenadas, de inteiras a incisas, planas a pouco ascendentes, pouco a não onduladas, sublacinuladas ou lobuladas apenas nas partes velhas centrais, de superfície irregularmente quebrada, de lisa a subrugosa devido às quebras; lacínulas ausentes ou raras, misturadas a lóbulos jovens irregulares e esparsos em partes velhas do centro, planos, estes curtos, 0,2-0,8 $\times$ 0,2-1,3 mm, simples ou irregulares, subarredondados, de lado de baixo concolorido à margem inferior; máculas laminais, distintas, puntiformes e agregadas, tornando- 
se em parte lineares e quase reticulares, às vezes formando manchas, originando quebras; cílios negros, simples a raramente furcados, $0,1-1,2 \times 0,05(-0,10)$ $\mathrm{mm}$, distribuídos por toda a margem, variando de poucos a frequientes dependendo dos trechos. Sorais e pústulas ausentes. Isídios de granulares a cilíndricos lisos, $0,05-0,35(-0,65) \times 0,05-0,10 \mathrm{~mm}$, de simples a ramificados tornando-se coralóides quando maiores, eretos, tortuosos, firmes, concoloridos ao córtex ou de ápices marrom-claros, não ornamentados ou raramente com ápices ciliados, surgindo em dobras do talo e espalhando-se pela lâmina, às vezes também marginais em alguns lobos. Medula branca, sem pigmentações. Lado de baixo marrom a marrom-escuro, negro em alguns pontos, lustroso, com áreas rugosas, venadas ou papiladas; margem marrom a marrom-clara, lustrosa, indistinta do centro ou em parte atenuada, 1,0-8,0 $\mathrm{mm}$ larg., em geral venada e papilada, em parte rizinada, algumas vezes lisa; rizinas concoloridas ou negras, dimórficas evidentes, agudas ou curvadas, as menores simples e mais finas $0,20-0,60 \times 0,05 \mathrm{~mm}$, as maiores mais espessas e ramificadas, 0,50-1,70 $\times 0,15-0,20$ $\mathrm{mm}$, freqüentes, homogeneamente distribuídas. Apotécios não encontrados. Picnídios submarginais escassos, de ostíolo negro; conídios filiformes curtos, 6,5-10,0 × ca. $1,0 \mu \mathrm{m}$.

Testes de coloração e substâncias de importância taxonômica: córtex superior K+ amarelo, UV(atranorina); medula $\mathrm{K}+$ alaranjado $\rightarrow$ vermelhoamarronzado ou marrom, $\mathrm{C}-, \mathrm{KC}-(\mathrm{K}$ apenas diluído por $\mathrm{C}$ ), $\mathrm{P}+$ alaranjado forte, UV- (ácidos protocetrárico, fumarprotocetrárico e traços de confumarprotocetrárico).

Distribuição: América do Sul. Brasil: BA, SP, PR, SC, RS (Hale 1986, Kurokawa 1991, Fleig 1997, Benatti 2005, Canêz 2005, Donha 2005).

Material estudado: BRASIL. SÃo PAUlo: Bertioga, Praia de Itararé, ao lado da antiga ponte sobre o Rio Itararé, no manguezal na margem sul, 13-I-1982, M.P. Marcelli 7 (isoparátipo SP); Peruíbe, margem esquerda do Rio Guaraú, no manguezal à beira do rio, 23-VII1988, M.P. Marcelli \& O. Yano 3921 (SP).

Parmotrema fumarprotocetraricumé caracterizada por ser isidiada, ter lado de baixo de marrom-claro a marrom-escuro ou, ocasionalmente, negro e apresentar ácidos protocetrárico, fumarprotocetrárico e confumarprotocetrárico na medula. Os isídios variam de simples a ramificados, e se tornam coralóides quando atingem as maiores dimensões (em geral aqueles com
0,5 mm ou mais de altura). São concoloridos ou amarronzados nos ápices, e eventualmente podem ser notados em pequena quantidade isídios com ápices ciliados em geral distantes uns dos outros.

Esta espécie tem uma morfologia extremamente semelhante à de Parmotrema neotropicum, compartilhando várias características tais como hábito e medidas de lobos e isídios. As reações químicas dos testes de coloração na medula são também semelhantes às de $P$. neotropicum, que possui como componentes químicos medulares os ácidos salazínico e consalazínico.

Testes de coloração podem apresentar variações em Parmotrema fumarprotocetraricum, inclusive se efetuados em pontos diferentes num mesmo espécime. Percebe-se que com a utilização de uma concentração menor de $\mathrm{KOH}$ (ca. 10\%) para o teste K, a medula reagiu laranja- claro $\rightarrow$ vermelho numa tonalidade amarronzada. Porém, ao utilizar solução mais saturada (ca. 30\%), observou-se uma reação laranja $\rightarrow$ marrom, característica do ácido fumarprotocetrárico, enquanto que em $P$. neotropicum a reação permaneceu $\mathrm{K}+$ vermelho forte mesmo assim. Já a diferença no teste $\mathrm{P}+$ é mais facilmente percebida, com um alaranjado forte ao invés de amarelo.

Donha (2005) apontou como diferença entre Parmotrema fumarprotocetraricum e P. neotropicum a coloração do lado de baixo do talo: a primeira com a margem variando de marrom a marrom-clara e o centro de marrom-escuro a negro, e a segunda com uma coloração uniformemente marrom a marromclara por todo o lado de baixo. Os espécimes de $P$. fumarprotocetraricum encontrados no litoral de São Paulo têm o lado de baixo exatamente como descrito em Hale (1986), Kurokawa (1991), Fleig (1997) e Donha (2005). Contudo, os espécimes de P. neotropicum descritos aqui também apresentam margens marrons com centro marrom-escuro a negro.

Inicialmente pensou-se que se tratava de $P$. subtinctorium, cujas descrições feitas por Hale (1965) e Kurokawa (1991) assemelham-se à de $P$. neotropicum, e que também é uma espécie que contém ácido salazínico na medula. Contudo, divergências verificadas quanto aos aspectos citados da morfologia e da química e as análises cromatográficas realizadas indicaram que os espécimes aqui examinados provavelmente pertencem a $P$. neotropicum (ver comentários sob esta espécie).

Hale (1986) mencionou que o ácido fumarprotocetrárico é incomum nas espécies de 
Parmeliaceae, citando outras poucas espécies contendo esta substância dentre as 228 conhecidas na época, e destacando apenas Parmotrema pardi e $P$. pseudograyanum, ambas sorediadas e de ocorrência no Velho Mundo. Não foi encontrada, na literatura, nenhuma outra espécie isidiada de Parmeliaceae contendo ácido fumarprotocetrárico. Um dos espécimes estudados (M.P. Marcelli 7) apresentou também traços de ácido confumarprotocetrárico. Kurokawa (1991) mencionou também que pode haver traços de ácido úsnico no córtex de $P$. fumarprotocetraricum, e que na descrição original de Hale (1986) esta substância pode ter passado despercebida. A substância não foi detectada na cromatografia do material estudado.

Parmotrema subisidiosum (Müll. Arg.) Hale difere de P. fumarprotocetraricum pelas máculas reticulares e rimosidade do córtex superior, pelos isídios comumente marginais, e pela presença dos ácidos salazínico e consalazínico na medula (Benatti 2005, Benatti \& Marcelli 2008). Notou-se que os espécimes de $P$. subisidiosum do litoral centro-sul de São Paulo têm ainda os isídios muito mais freqüentemente ciliados que os de $P$. fumarprotocetraricum.

Devido à semelhança morfológica, apesar da diferença observada nos testes de coloração, $P$. fumarprotocetraricum só pode ser separada com certeza de $P$. neotropicum após cromatografia.

Parmotrema neotropicum Kurokawa in Hale, Mycotaxon 5(2): 437. 1977. Tipo: MÉXICO. Chiapas: oeste de São Cristóbal, Hale 20190 (holótipo US n.v.).

Figuras 3a, b

Talo sublobado, verde-acinzentado a pardoesverdeado quando em herbário, até 17,0 cm diâm., subcoriáceo, corticícola; lobos de ramificação irregular, 2,0-9,0(-11,0) mm larg., de superfície irregularmente quebrada, lisa a rugosa pelas quebras, sobrepostos lateralmente a pouco amontoados no centro do talo, de adnatos a pouco elevados, de adpressos a pouco adpressos, os ápices subarredondados, planos a subplanos, as margens crenadas, incisas, subascendentes, pouco ou não onduladas, sublacinuladas ou lobuladas apenas nas partes velhas centrais; lacínulas ausentes ou raras, misturadas com alguns lóbulos jovens irregulares esparsos a abundantes em partes velhas do centro, planos, 0,2-2,7 ×0,2-2,5 mm, simples ou irregulares, subarredondados, lado de baixo concolorido à margem inferior; máculas em geral distintas, puntiformes, agregadas, tornando-se em parte lineares quase reticulares, às vezes formando manchas, laminais, originando quebras; cílios negros, simples a raramente furcados, 0,10-1,50 × 0,05(-0,10) $\mathrm{mm}$, distribuídos por toda a margem, variando de poucos, frequientes ou às vezes abundantes em alguns trechos. Sorais e pústulas ausentes. Isídios de granulares a cilíndricos lisos, 0,05-0,65(-1,20) × 0,05-0,10 mm, de simples a ramificados ou coralóides quando maiores, eretos, firmes, tortuosos, concoloridos ao córtex ou de ápices marrons, não ornamentados na maioria mas às vezes de ápices ciliados, surgindo em dobras do talo e espalhando-se pela lâmina, às vezes também marginais em alguns lobos. Medula branca, sem pigmentações. Lado de baixo marrom-escuro a negro, lustroso, rugoso, venado ou papilado; margem marrom a marrom-clara, lustrosa, indistinta do centro ou em parte atenuada, 1,0-10,0 mm larg. quando atenuada, poucas vezes lisa, em geral venada e papilada e em parte rizinada; rizinas concoloridas ou negras, dimórficas, agudas ou curvadas, as menores simples e mais finas $0,20-0,70 \times 0,05 \mathrm{~mm}$, as maiores mais espessas e ramificadas $0,6-1,80(-2,50) \times 0,10(-0,15)$ $\mathrm{mm}$, freqüentes, homogeneamente distribuídas. Apotécios ausentes. Picnídios submarginais, escassos, de ostíolo negro; conídios filiformes curtos, 6,5-9,0 $\mu \mathrm{m} \times$ ca. $1,0 \mu \mathrm{m}$.

Testes de coloração e substâncias de importância taxonômica: córtex superior $\mathrm{K}+$ amarelo, UV(atranorina, às vezes também com traços de ácido úsnico); medula $\mathrm{K}+$ alaranjado $\rightarrow$ vermelho-sangue, $\mathrm{C}-, \mathrm{KC}-$ (K diluído por $\mathrm{C}$ ), $\mathrm{P}+$ amarelo, $\mathrm{UV}$ - (ácido salazínico).

Distribuição: Pan-americana. Brasil: PE, GO, MG, RJ, SP, RS, (Marcelli 1987, Kurokawa 1991, Fleig 1997, Ribeiro 1998, Benatti 2005).

Material estudado: BRASIL. São Paulo: Bertioga, Praia de Itararé, ao lado da antiga ponte sobre o Rio Itararé, no manguezal, 25-III-1980, M.P. Marcelli \& J.A. Ambraska 1682 (SP); idem, Praia de Guaratuba, à beira do Rio Guaratuba, no cruzamento com a antiga rodovia, manguezal à beira do rio na margem esquerda, 26-XII-1981, M.P. Marcelli 1683 (SP); Itanhaém, Rodovia Padre Manoel da Nóbrega (SP55) $\mathrm{km} \mathrm{108,} \mathrm{no} \mathrm{cruzamento} \mathrm{sob} \mathrm{o} \mathrm{Rio} \mathrm{Itanhaém,}$ manguezal na margem direita do rio ao lado da rodovia, 10-I-1979, M.P. Marcelli \& L.R. Fontes 1680 (SP); idem, 10-I-1979, M.P. Marcelli \& L.R. Fontes 1685 (SP); idem, Bairro Nova Itanhaém, ca. 
$5 \mathrm{~km}$ ao norte do centro da cidade, a 200 metros da praia, restinga em terreno baldio, 17-XII-1989, M.P. Marcelli \& O. Yano 4711 (SP); idem, manguezal na foz do Rio Itanhaém, às margens do rio próximo à ponte velha na Rodovia Padre Manoel da Nóbrega (SP-55), manguezal na margem direita do rio, 15-X2003, M.N. Benatti et al. 1637 (SP); Peruíbe, margem esquerda do Rio Guaraú, no manguezal à beira do rio, 23-VII-1988, M.P. Marcelli \& O. Yano 3914 (SP); idem, 23-VII-1988, M.P. Marcelli \& O. Yano 3923 (SP); idem, 23-VII-1988, M.P. Marcelli \& O. Yano 3935 (SP); idem, 23-VII-1988, M.P. Marcelli \& O. Yano 3954 (SP); idem, 23-VII-1988, M.P. Marcelli \& O. Yano 3983 (SP).

Parmotrema neotropicum é caracterizada pelos isídios laminais que surgem dos ápices de dobras e que se espalham pela lâmina (também aparecendo com menos frequiência nas margens), e pela presença do ácido salazínico (K+ amarelo $\rightarrow$ vermelho, $\mathrm{P}+$ amarelo) na medula. Kurokawa (1991) comenta que parte dos isídios podem ser apicalmente ciliados nesta espécie, o que pode ser percebido ainda com mais facilidade do que no material de $P$. fumarprotocetraricum.

Parmotrema fumarprotocetraricum é uma espécie isidiada muito parecida, não tendo sido encontrada uma diferença morfológica constante que pudesse ser utilizada para sua diferenciação. Nesta espécie, os isídios parecem estar mais restritos aos ápices das dobras do que foi percebido em $P$. neotropicum, também aparecendo com ainda menos freqüência nas margens. Apesar desta comparação visual, não foi encontrado material suficiente para certificação de que de fato haja alguma diferença consistente no padrão de distribuição dos isídios das duas espécies. A principal diferença está na química medular, pois $P$. fumarprotocetraricum apresenta ácidos protocetrárico e fumarprotocetrárico $(\mathrm{K}+$ laranja $\rightarrow$ marrom, $\mathrm{P}+$ alaranjado), este último sendo raro em espécies de Parmeliaceae (Hale 1986).

Pelas descrições de Hale (1965) e Kurokawa (1991), Parmotrema subtinctorium é semelhante morfológica e quimicamente a $P$. neotropicum, mas existem divergências sobre os caracteres que as aproximam. A coloração do lado de baixo de P. neotropicum foi descrita por Hale (1986) como uniformemente marrom ("omnius castaneus"), enquanto que Kurokawa (1991) e Fleig (1997) a descrevem como negra a marrom-escura no centro (ao menos num espaço mais estrito) e de margens marrons. Esta última é a mais semelhante ao lado de baixo dos espécimes aqui estudados, e também dos de $P$. fumarprotocetraricum.

Quanto à química, Hale (1965) e Kurokawa (1991) citam que Parmotrema subtinctorium apresenta norlobaridona e loxodina como compostos medulares característicos, que não foram detectados nos espécimes cromatografados aqui. Já foram atribuídos a $P$. subtinctorium dois diferentes tipos químicos (Hale 1965, Kurokawa 1991), com um grupo contendo o ácido salazínico, norlobaridona e loxodina, e o outro somente norlobaridona e loxodina. Este último era anteriormente tido como a espécie Parmelia haitiensis Hale (Hale 1959), mais tarde sinonimizada pelo próprio autor (Hale 1965) sob Parmelia subtinctoria, que considerou os grupos como tipos químicos da mesma espécie. Kurokawa (1991) aceitou essa idéia por também acreditar que o ácido salazínico fosse uma substância acessória na espécie, e que norlobaridona e loxodina seriam os compostos principais. Entretanto, o próprio Hale (1965) já apontava que a distribuição do grupo sem ácido salazínico era restrita às Américas.

Elix (1993) combinou Parmelia [Parmotrema] haitiensis em Rimeliella, porém não comentou as considerações feitas anteriormente por Kurokawa (1991), e posteriormente transferiu separadamente Rimeliella [Parmotrema] haitiensis e Rimeliella [Parmotrema] subtinctoria para o gênero Canomaculina (Elix 1997). Fleig (1997) comentou que Elix, ao recombiná-las, separou as espécies pela composição química e pela ocorrência, Canomaculina [Parmotrema] haitiensis contendo norlobaridona e loxodina e ocorrendo nas Américas, e Canomaculina [Parmotrema] subtinctoria contendo norlobaridona, loxodina e ácido salazínico e ocorrendo na África e na Ásia. Porém, o comentário de Fleig pareceu uma combinação dos comentários de Hale (1965) ao procedimento de Elix (1997), que se restringiu somente a fazer a recombinação e em nenhum momento fez qualquer comentário a respeito da química ou da distribuição geográfica das espécies.

Além destas diferenças, segundo Hale (1965) e Kurokawa (1991), Parmotrema subtinctorium (e provavelmente também $P$. haitiensis, vide comentários sob $P$. subcaperatum) têm lobos mais largos (5,0-15,0 mm) e mais arredondados que os de P. neotropicum. Nenhum espécime de Parmotrema contendo norlobaridona e loxodina foi encontrado na área de estudo.

Parmotrema subisidiosum difere de $P$. neotropicum pela presença de máculas reticulares 
e pela rimosidade no córtex superior, pelos isídios comuns nas margens, avançando sobre a lâmina nos trechos submarginais e surgindo por sobre dobras do talo, e pelo lado de baixo sempre negro no centro, com as margens marrons (Benatti 2005, Benatti \& Marcelli 2008).

Kurokawa (1991) mencionou que podem ser encontrados traços de ácido úsnico no córtex superior de alguns espécimes de $P$. neotropicum, embora afirme que, em virtude da quantidade variável, a substância não é sempre detectada, podendo inclusive estar ausente. Somente um espécime (M.P. Marcelli 4711 ) entre os aqui estudados mostrou conter ácido úsnico cortical após a cromatografia, porém, não foi encontrada qualquer diferença morfológica entre este e os demais espécimes estudados.

Parmotrema subcaperatum (Kremp.) Hale, Phytologia 28(4): 339.1974 三 Parmelia subcaperata Kremp., Nat. For. Kjoeb. Vid. Medd. 1-4:10. 1873. Tipo: BRASIL. Minas Gerais: Serra da Piedade, Lagoa Santa, E. Warming 297 (holótipo M, n.v.).

Figuras 4a, b

Talo sublobado, verde-acinzentado a pardoesverdeado quando em herbário, de até $15,0 \mathrm{~cm}$ diâm., subcoriáceo, saxícola; lobos de ramificação irregular, (1,5-)2,5-8,0(-10,0) mm larg., de superfície contínua tornando-se irregularmente quebrada em direção ao centro, lisa a pouco rugosa, de sobrepostos lateralmente a amontoados no centro do talo, pouco elevados e pouco adpressos, os ápices subarredondados, planos a subcôncavos ou às vezes revolutos, as margens crenadas e bastante incisas, pouco a moderadamente ascendentes, pouco onduladas, sublacinuladas mais para o centro do talo; lacínulas irregularmente distribuídas pela margem, mais comuns nos lobos amontoados no centro do talo misturadas a lóbulos jovens irregulares, planas, 0,3-4,2 × 0,2-2,5 mm, simples, furcadas ou irregulares, truncadas ou às vezes agudas, lado de baixo concolorido à margem inferior do talo; máculas fracas a distintas, puntiformes a raramente lineares, laminais, muito raramente originando quebras; cílios negros, simples a raramente furcados, 0,1$2,0 \times 0,05(-0,10) \mathrm{mm}$, abundantes, distribuídos por toda a margem. Sorais, pústulas e isídios ausentes. Medula branca, sem pigmentações. Lado de baixo marrom claro, mais escuro nas partes muito rizinadas, lustroso, liso, pouco venado ou papilado; margem sem limite aparente e mesclando-se com o centro, marrom-clara, lustrosa, lisa, pouco venada, papilada, rizinada; rizinas negras ou marrons muito escuras, dimórficas, em geral curvadas, as menores simples e mais finas, as maiores e mais espessas de ápices ramificados ou irregulares, 0,2-2,1 × 0,05-0,10 mm, abundantes, homogeneamente distribuídas. Apotécios côncavos a cupuliformes, 0,3-8,3 mm, submarginais ou às vezes laminais, subpedicelados, de margem
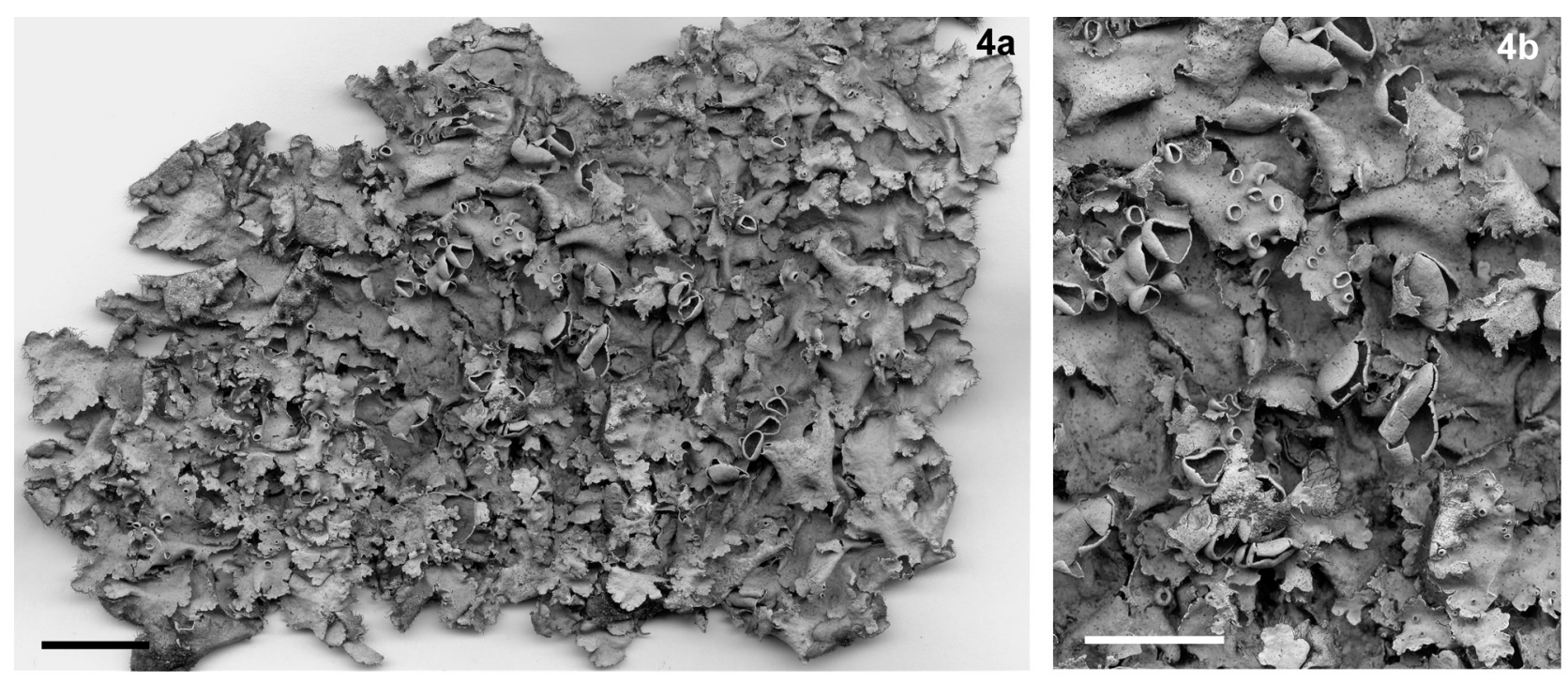

Figura 4. Parmotrema subcaperatum a. Hábito. b. Detalhe (Marcelli 23772). Barras de escala $=1 \mathrm{~cm}$. 
lisa não ornamentada, o anfitécio liso, fendido e com as margens involutas quando velho; disco marrom, côncavo a cupuliforme, não pruinoso, perfurado a imperfurado; esporos elipsóides, 14,0-16,0(-19,0) $\times$ 9,0-11,0(-14,0) $\mu \mathrm{m}$, epispório 1,0 $\mu \mathrm{m}$. Picnídios submarginais ou raramente laminais, de ostíolo negro; conídios baciliformes a filiformes curtos, 5,0-9,0(11,5) $\times$ ca. $1,0 \mu \mathrm{m}$.

Testes de coloração e substâncias de importância taxonômica: córtex superior $\mathrm{K}+$ amarelo, UV(atranorina); medula $\mathrm{K}+$ alaranjado $\rightarrow$ vermelhosangue, $\mathrm{C}-, \mathrm{KC}-(\mathrm{K}$ diluído por $\mathrm{C}), \mathrm{P}+$ amarelo, UV- (ácidos salazínico e consalazínico).

Distribuição: Oceania e América do Sul. Brasil: MG, MS, SP, RJ, PR, RS (Kurokawa 1991, Osorio 1992, Fleig 1997, Ribeiro 1998, Benatti 2005).

Material estudado: BRASIL. São PAulo: Peruíbe, Reserva Ecológica Juréia-Itatins, Núcleo Guarauzinho, no sopé da Serra do Mar, na Praia do Arpoador, costão rochoso no lado norte, 29-VII-1993, M.P. Marcelli \& O. Yano 23772 (SP).

Parmotrema subcaperatum é caracterizada pela total ausência de propágulos vegetativos no talo, lado de baixo que varia de marrom-claro (na maior parte) a marrom-escuro, e pela presença dos ácidos salazínico e consalazínico como constituintes químicos medulares.

Segundo Kurokawa (1991) e Fleig (1997), às vezes podem ser detectados traços de ácido úsnico cortical. Fleig (1997) citou que a presença desta substância é bastante comum nos espécimes do Rio Grande do Sul, não ocorrendo o mesmo (Eliasaro 2001) com os espécimes do Paraná. Ainda, Kurokawa (1991) e Fleig (1997) citam lobos mais largos (0,5-2,0 $\mathrm{cm})$ do que os observados aqui. O único espécime encontrado continha apenas atranorina cortical.

Os conídios são muito pequenos para o padrão do gênero, tendo tamanho um tanto menor do que o comumente citado na literatura, que é de (7,5-)10,015,0(-17,0) um (Kurokawa 1991, Fleig 1997, Ribeiro 1998, Eliasaro 2001). Esta espécie não é, contudo, a única com conídios abaixo das medidas típicas. $\mathrm{Na}$ descrição do gênero Canomaculina Elix \& Hale (1987) são citados conídios de 12 a $16 \mu \mathrm{m}$ de comprimento para o gênero. A amplitude mudou para 8 a 16 um após a constatação feita por Elix (1997) de que Rimeliella Kurokawa era um sinônimo de Canomaculina. Porém, Canomaculina [Parmotrema] tandilensis forma conídios similares aos de $P$. subcaperatum, variando de 5,0-11,0 um (Adler \& Elix 1987), também abaixo das medidas padrão mencionadas para o gênero.

Segundo as descrições de Hale (1965) e Kurokawa (1991), Parmotrema recipiendum (Nyl.) Hale [respectivamente tratada pelos autores como Parmelia recipienda Nyl. e Rimeliella recipienda (Nyl.) Kurok.] é morfologicamente similar a $P$. subcaperatum, tendo sido sinonimizadas pelo autor quando este aceitou dois grupos químicos diferentes para uma mesma espécie: um com ácido salazínico e outro com ácido criptoclorofeico (posteriormente constatou-se que na verdade se tratava de norlobaridona). Quase dez anos depois, o próprio Hale (1974) recombinou as duas espécies em separado no gênero Parmotrema, porém sem qualquer comentário a respeito ou explicação da razão do procedimento.

Quando Kurokawa (1991) transferiu Parmotrema recipiendum e algumas outras espécies para o novo gênero Rimeliella, notou os caracteres morfológicos que distinguiam $P$. subcaperatum de $P$. recipiendum bem como as respectivas diferenças químicas, pela presença de ácido salazínico e consalazínico na primeira e de norlobaridona e loxodina $(\mathrm{KC}+$ róseo forte a avermelhado) na segunda. $\mathrm{O}$ autor também não encontrou uma variedade que possuísse todas as substâncias acima citadas, embora essa tivesse sido mencionada por Hale (1965) ao sinonimizar as espécies.

Houve uma explicação, segundo Kurokawa (1991), para o equívoco cometido por Hale (1965) ao ter tentado identificar a composição química medular de Parmelia recipienda (Parmotrema recipiendum). $\mathrm{Na}$ verdade, seu segundo grupo químico não foi discernido através de cromatografia, mas por testes de microcristalização, que levaram então Hale (1965) a interpretar os cristais de norlobaridona e loxodina como de ácidos criptoclorofeico e graxos.

Como outra diferença aparente entre $P$. recipiendum e $P$. subcaperatum, Fleig (1997) citou esporos menores $(10,0-13,0 \mu \mathrm{m} \times 6,0-8,0 \mu \mathrm{m}) \mathrm{e}$ conídios maiores $(8,0-15,0 \mu \mathrm{m})$ para seu material, enquanto Kurokawa (1991) citou esporos maiores (12,0-19,0 × 6,0-10,0 um) para P. recipiendum, porém sem citar conídios.

Segundo Kurokawa (1991) e Ferraro \& Elix (2000), P. uruguense (Kremp.) Hale também tem o córtex inferior semelhante ao de $P$. subcaperatum, mas tem apotécios com anfitécio ciliado, e as rizinas são esparsamente ramificadas, tornando-se aglomeradas e intrincadas. Fleig (1997) citou esporos menores $(10,0-12,0 \times 6,0-7,5 \mu \mathrm{m})$ e conídios maiores $(10,0$ - 
15,0 $\mu \mathrm{m}$ compr.) que os vistos aqui no espécime de P. subcaperatum.

Parmotrema cristobalii (Ferraro \& Elix) Blanco et al. e P. laciniellum (Ferraro \& Elix) Blanco et al. podem ser diferenciadas principalmente pelos lobos muito lacinulados. A primeira também difere pelos conídios em geral maiores $(10,0-14,0 \mu \mathrm{m})$ e pela química medular, que apresenta norlobaridona e loxodina além dos ácidos salazínico e consalazínico; a segunda tem ainda lobos originando lacínulas regularmente a partir dos ápices e das margens (Ferraro \& Elix 1993, 2000).

Kurokawa (2001) diferenciou $P$. reparatum [Canomaculina reparata], uma espécie similar sinonimizada em Parmotrema subcaperatum [Canomaculina subcaperata] por DePriest \& Hale (1999), pelo córtex inferior todo negro com apenas uma estreita zona marginal castanha. O autor citou ainda que o dimorfismo nas rizinas não é tão freqüente na primeira como é na segunda, estando restrito a alguns lobos e não disseminado por todo o lado de baixo. Para Kurokawa (2001), P. subcaperatum seria uma espécie tipicamente sul-americana, e o material australiano e neozelandês pertenceria a $P$. reparatum, confusamente interpretada como $P$. subcaperatum.

Parmotrema cetratum difere por ter máculas reticulares e córtex superior rimoso rachado, cílios e rizinas simples a esquarrosos, apotécios imperfurados a perfurados, e lado de baixo negro com margens marrons (Benatti 2005, Benatti \& Marcelli 2008).

As espécies aqui descritas do grupo com rizinas dimórficas estão de acordo com o senso mais amplo utilizado por Elix (1997), ao definir mais explicitamente o gênero Canomaculina.

Os cílios normalmente são simples ou parcialmente furcados. As lacínulas não são comuns no grupo, e o que na maioria das espécies encontradas aparentam ser lacínulas, são geralmente lóbulos jovens e irregulares crescendo em partes envelhecidas do talo.

O padrão de distribuição e o formato das máculas são características marcantes do grupo. Estas são laminais, efiguradas, puntiformes, variam de fracas a distintas (visíveis principalmente nos apotécios), e se espalham por toda a superfície do córtex superior, às vezes aglomerando-se e parecendo lineares, ocasionalmente originando rachaduras em áreas velhas dos talos de algumas espécies. Estas máculas não são reticulares e não ocasionam rimosidade no córtex, como as máculas observadas no grupo das espécies de Parmotrema que formava o gênero Rimelia.

As rizinas quase sempre apresentam dimorfismo muito evidente. Embora o misto de rizinas simples, curtas e finas com rizinas longas, espessas e de ápices ramificados seja perceptível em todas as espécies, apenas em $P$. consors ele não é tão evidente quanto nas demais. Há, nesta espécie, uma variação com mais tamanhos intermediários do que o visto nas outras, em que as rizinas, apesar de misturadas, são muito díspares no aspecto e são facilmente evidenciadas.

Os apotécios são subpedicelados, variando de totalmente perfurados desde jovens (em $P$. consors) a parcialmente perfurados (em P. subcaperatum). Não são ornamentados e são sempre eciliados. Parte do material não apresentou esporos ou mesmo ascos, sendo que vários dos espécimes continham apenas apotécios muito jovens.

O ácido salazínico medular pode sofrer hidrólise e oxidação e formar manchas de um vermelho ferruginoso nos talos (semelhante à cor de sangue coagulado) que antes de uma análise química podem ser confundidas com alguma pigmentação como do tipo antraquinona. Entretanto, não houve reação destas manchas aos testes de coloração, cuja aplicação resultou apenas no encharcamento da medula. Estas manchas não ocorrem em $P$. fumarprotocetraricum, muito semelhante na morfologia a $P$. neotropicum, e provaram ser uma característica útil para constatar a ausência do ácido salazínico, cuja reação de coloração se assemelha à do ácido fumarprotocetrárico.

Walker \& James (1980), Hüneck \& Yoshimura (1996) e Orange et al. (2001) sugerem a utilização de $\mathrm{KOH}$ em concentrações variando de $10 \%$ a $30 \%$ (saturada). Os resultados aqui apresentados com a tentativa de separar por testes de coloração o ácido fumarprotocetrárico do salazínico sugerem que sempre se utilize a solução saturada (quando se verifica a precipitação dos cristais) para diferenciar claramente os ácidos.

\section{Agradecimentos}

Os autores agradecem à assessoria pelas contribuições e revisão do trabalho e ao Conselho Nacional de Desenvolvimento Científico e Tecnológico (CNPq) pelas bolsas de mestrado e de pesquisa concedidas, respectivamente, ao segundo e primeiro autores. 


\section{Literatura citada}

Adler, M.T. \& Elix, J.A. 1987. Three new saxicolous species in Parmeliaceae (Lichenized Ascomycotina). Mycotaxon 30: 339-344.

Asahina, Y. \& Shibata, S. 1954. Chemistry of lichen substances. Japan Society for the Promotion of Science, Tóquio.

Benatti, M.N. 2005. Os gêneros Canomaculina, Parmotrema e Rimelia (Parmeliaceae, Ascomycetes) no litoral centro-sul do estado de São Paulo. Dissertação de Mestrado, Instituto de Botânica, São Paulo.

Benatti, M.N. \& Marcelli, M.P. 2008. As espécies de Parmotrema (Parmeliaceae, Ascomycetes liquenizados) com máculas reticulares do litoral centro-sul do estado de São Paulo. Hoehnea 35(1): 75-90.

Blanco, O., Crespo, A., Divakar, P.K., Elix, J.A. \& Lumbsch, H.T. 2005. Molecular phylogeny of parmotremoid lichens (Ascomycota, Parmeliaceae). Mycologia 97: 150-159.

Bungartz, F. 2001. Analysis of lichen substances. http:// ces.asu.edu/ASULichens/plb 400/ laboratory/chemistry/ tlc.html (acesso em 01.10.2004).

Canêz, L.S. 2005. A Família Parmeliaceae na localidade de Fazenda da Estrela, Município de Vacaria, Rio Grande do Sul, Brasil. Dissertação de Mestrado, Instituto de Botânica, São Paulo.

DePriest, P.T. \& Hale, B.W. 1999. Mason’s E. Hale list of epithets in the Parmelioid genera. The Bryologist 102: 462-544.

Donha, C.G. 2005. Os gêneros Canomaculina, Parmotrema e Rimelia (Ascomycota Liquenizados) na Área de Proteção Ambiental de Guaraqueçaba, Paraná, Brasil. Dissertação de Mestrado, Universidade Federal do Paraná, Curitiba.

Eliasaro, S. 2001. Estudio taxonomico y floristico sobre las Parmeliaceae sensu stricto (Ascomycota liquenizados) del Segundo Planalto del Estado de Paraná, Brasil. Tese de Doutorado, Universidad de Buenos Aires, Buenos Aires.

Eliasaro, S. \& Adler, M.T. 2000. The species of Canomaculina, Myelochroa, Parmelinella, and Parmelinopsis (Parmeliaceae, lichenized Ascomycotina) from the "Segundo Planalto" in the State of Paraná, Brazil. Acta Botanica Brasilica 14: 141-149.

Eliasaro, S. \& Donha, C.G. 2003. The genera Canomaculina and Parmotrema (Parmeliaceae, lichenized Ascomycota) in Curitiba, Paraná State, Brazil. Revista Brasileira de Botânica 26: 239-247.

Elix, J.A. 1993. New species in the lichen family Parmeliaceae (Ascomycotina) from Australia. Mycotaxon 47: 101-129.

Elix, J.A. 1994. Canomaculina. In: A.E. Orchard \& C. Grurinovic (eds.). Flora of Australia, Lichens.
Introduction, Lecanorales 2. Australia Government Publishing Service, Canberra. v. 55, pp. 20-21.

Elix, J.A. 1997. The lichen genera Canomaculina and Rimeliella (Ascomycotina: Parmeliaceae). Mycotaxon 65: 475-479.

Elix, J.A. \& Hale, M.E. 1987. Canomaculina, Myelochroa, Parmelinella, Parmelinopsis and Parmotremopsis, five new genera in the Parmeliaceae (lichenized Ascomycotina). Mycotaxon 29: 233-244.

Fink, B. 1905. How to collect and study lichens. The Bryologist 8: 22-27.

Ferraro, L.I. \& Elix, J. 1993. Two new species of Parmeliaceae (Lichenized Ascomycotina) from South America. Mycotaxon 49: 405-409.

Ferraro, L.I. \& Elix, J. 2000. Anew species of Canomaculina (Lichenized Ascomycotina, Parmeliaceae) from Argentina. Mycotaxon 74: 391-394.

Fleig, M. 1997. Os gêneros Parmotrema, Rimelia e Rimeliella (Lichenes-Ascomycota, Parmeliaceae) no Rio Grande do Sul, Brasil. Tese de Doutorado, Universidade de São Paulo, São Paulo.

Galloway, D.J. 1985. Flora of New Zealand - lichens. Government Printer. Wellington.

Hale, M.E. 1959. New or interesting species of Parmelia in North America. The Bryologist 62: 16-24.

Hale, M.E. 1965. A monograph of the Parmelia subgenus Amphigymnia. Contributions from the United States National Herbarium 36: 193-358.

Hale, M.E. 1974. New combinations in the lichen genus Parmotrema Massalongo. Phytologia 28: 334-339.

Hale, M.E. 1976. A monograph of the lichen genus Parmelina Hale (Parmeliaceae). Smithsonian Contributions to Botany 33: 1-60.

Hale, M.E. 1979. How to know the Lichens. The PicturedKey Nature Series. Wm. C. Brown Company Publishers, Dubuque.

Hale, M.E. 1986. New species in the lichen family Parmeliaceae (Ascomycotina). Mycotaxon 25: 85-93.

Huneck, S. \& Yoshimura, I. 1996. Identification of lichen substances. Springer, Berlin.

Jungbluth, P. 2006. A família Parmeliaceae (fungos liquenizados) em fragmentos de cerrados do Estado de São Paulo. Dissertação de Mestrado, Instituto de Botânica, São Paulo.

Kurokawa, S. 1991. Rimeliella, a new genus related to Rimelia of the Parmeliaceae. Annals of the Tsukuba Botanical Garden 10: 1-14.

Kurokawa, S. 2001. Taxonomic notes on Parmelia reparata (Parmeliaceae, Lichenes) and the related species. Bulletin of the Natural Science Museum of Tokyo, ser. B, 27: 1-10.

Marcelli, M.P. 1987. Ecologia dos liquens dos manguezais da região sul-sudeste do Brasil, com especial atenção 
ao de Itanhaém (SP). Tese de Doutorado, Universidade de São Paulo, São Paulo.

Marcelli, M.P. 2005. Checklist of Brazilian lichens. Publicação na Internet, pela Universität Hamburg Institut für Allgemeine Botanik, dentro do programa South American Lichens Online. http://www.rra.unihamburg.de/biologie/ialb/herbar/brazi_f2.htm (acesso em 01.03.2005).

Orange, A., James, P.W. \& White, F.J. 2001. Microchemical methods for the identification of lichens. The British Lichen Society, London.

Osorio, H.S. 1992. Contribution to the lichen flora of Brazil. XXIX. Comunicaciones Botánicas del Museo de Historia Natural de Montevideo 5: 1-6.

Ribeiro, C.H. 1998. A família Parmeliaceae (Ascomycota liquenizados) em regiões montanhosas dos estados de Minas Gerais, Rio de Janeiro e São Paulo. Dissertação de Mestrado, Universidade de São Paulo, São Paulo.
Sipman, H.J.M. 2004. Mason Hale's key to Parmotrema, revised edition: key to wide-lobed parmelioid species occurring in Tropical America (genera Canomaculina, Parmotrema, Rimelia, Rimeliella). http://www. bgbm.org/sipman/keys/neoparmo.htm. (acesso em 01.07.2005).

Spielmann, A.A. 2005. A família Parmeliaceae (fungos liquenizados) nos barrancos e peraus da encosta da Serra Geral, no Vale do Rio Pardo, Rio Grande do Sul, Brasil. Dissertação de Mestrado, Instituto de Botânica, São Paulo.

Walker, J.W. \& James, P.W. 1980. A revised guide to microchemical techniques for the identification of lichen products. Bulletin of the British Lichen Society 46 (suppl.): 13-29.

White, F.J. \& James, P.W. 1985. A new guide to microchemical techniques for the identification of lichen substances. British Lichen Society Bulletin 57 (suppl.): 1-41. 